\title{
Bebida eletrolítica a base de permeado da ultrafiltração de leite: avaliação física, química e microbiológica durante o armazenamento
}

\author{
Milk ultrafiltration permeate-based electrolyte drink: physical, chemical and microbiological \\ assessment during storage
}

\author{
Edimar Aparecida Filomeno Fontes ${ }^{I^{*}}$ Yara Pereira Cerceau Alves ${ }^{\mathrm{I}}$ \\ Paulo Rogério FontesII Valéria Paula Rodrigues Minim ${ }^{I}$
}

\section{RESUMO}

Este trabalho teve como objetivo a elaboração de uma bebida eletrolitica a base de permeado da ultrafiltração de leite e avaliação de suas características físicas, químicas e microbiológicas, durante o periodo de armazenamento por 30 dias, nas temperaturas de $7^{\circ} \mathrm{C}$ e $25^{\circ} \mathrm{C}$. A bebida apresentouse clara, com coloração amarelo-esverdeada, osmolalidade de 311,6mOsmol. L $^{-1}$ e carboidratos totais de $6,48 \% \mathrm{~m} / \mathrm{v}$. Não foram observadas alterações significativas de $\mathrm{pH}$, acidez titulável e sólidos solúveis durante o tempo e temperatura de armazenamento $(P>0,05)$. A osmolalidade e o teor de açúcares totais foram afetados pelo tempo $(P<0,05)$, enquanto que o aumento de açúcares redutores foi afetado pelo tempo e pela temperatura de armazenamento $(P<0,05)$. Observou-se correlação positiva $(P<0,05)$ entre o teor de açúcares redutores e totais com a osmolalidade,porém a bebida manteve-se dentro da faixa de osmolalidade(entre $290 \mathrm{mOsm} \mathrm{L} \mathrm{L}^{-1}$ e $330 \mathrm{mOsm} \mathrm{L} \mathrm{L}^{-1}$ ). As coordenadas $L^{*}, a^{*}, b^{*} e C^{*}$ foram afetadas somente pelo tempo de armazenamento $(P<0,05)$. No estudo de vida útil, a bebida mostrou-se estável microbiologicamente. Assim, o permeado pode ser aproveitado como coproduto industrial na elaboração de bebidas eletroliticas, em vista dos critérios de osmolalidade, além de conter minerais naturais.

Palavras-chave: minerais, osmolalidade, cor, soro de leite, bebida não alcoolica.

\section{ABSTRACT}

This study aimed to prepare a electrolyte drink based on permeate of milk ultrafiltration with evaluation of its physical, chemical, and microbiological properties during 30 days of storage at $7{ }^{\circ} \mathrm{C}$ and $25^{\circ} \mathrm{C}$. The drink became clear, with greenish-yellow color, osmolality of $311.6 \mathrm{mOsmol} \mathrm{L}^{-1}$ and total carbohydrates of $6.48 \% \mathrm{~m} / \mathrm{v}$. There were no significant changes in $\mathrm{pH}$, titratable acidity, and soluble solids during storage time and temperature $(P>0.05)$. The osmolality and total sugars were affected by time $(P<0.05)$, whereas the increase in reducing sugars was affected by storage temperature and time $(P<0.05)$. Positive correlation $(P<0.05)$ between total reducing sugars and osmolality was observed, but the drink was within

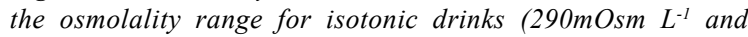
$\left.330 \mathrm{mOsm} L^{-1}\right) . L^{*}, a^{*}, b^{*}$, and $C^{*}$ coordinates were affected only by the storage time $(P<0.05)$. In the study of shelf life, the drink showed to be microbiologically stable. The permeate can be used as industrial residue in the preparation of electrolyte drinks in view of osmolality criteria, besides containing natural minerals.

Key words: minerals, osmolality, color, milk whey, non-alcoholic drink.

\section{INTRODUÇÃO}

A utilização da ultrafiltração por membrana na indústria de laticínios possibilita o desenvolvimento de novos produtos e o aproveitamento total e seletivo de todos os componentes do leite. Este processo vem sendo muito utilizado na concentração de proteínas do soro, na fabricação de queijos diferenciados com melhores características nutricionais, sensoriais e microbiológicas (VEIGA \& VIOTTO, 2001; NETO, 2006).

A ultrafiltração compreende um processo de separação por membrana, tipicamente usado para retenção de macromoléculas do leite, permitindo uma variação na concentração dos componentes do soro de leite ou leite, devido à retenção de proteínas

\footnotetext{
IDepartamento de Tecnologia de Alimentos, Universidade Federal de Viçosa (UFV), Av. PH Rolfs, s/n, 36570-000, Viçosa, MG, Brasil. E-mail: eaffontes@ufv.br. *Autor para correspondência.

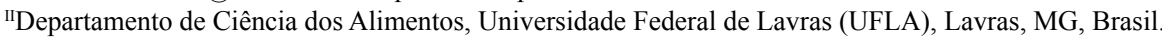
Recebido 28.10.13 Aprovado 02.07.14 Devolvido pelo autor 24.09.14 CR-2013-1432.R1
} 
e permeabilidade seletiva de lactose, minerais, água e compostos de baixa massa molar (BALDASSO et al., 2011). Este permeado obtido tem características osmolíticas e apresenta nutrientes naturais, o que mostra ser promissora a sua utilização como base na formulação de produtos destinados a auxiliar a hidratação após atividade física.

Além disso, o enorme volume de permeado da ultrafiltração, gerado na indústria láctea, constitui um problema, haja vista que este geralmente é descartado em efluentes e possui alto potencial poluente, devido à elevada demanda bioquímica de oxigênio provocada pela lactose (SARON, 2003) e apresenta pouca ou nenhuma aplicação industrial. Por isso, novas aplicações a fim de agregar valor ao permeado devem ser estudadas.

Os repositores hidroeletrolíticos, de acordo com a Resolução RDC nº18, de 27 de Abril de 2010 da ANVISA (2010), são suplementos especialmente formulados para praticantes de atividades físicas, com o objetivo de reposição hídrica e eletrolítica. Em todo o mundo, há um grande esforço em preparar bebidas isotônicas, adicionadas de nutrientes essenciais para tratamento de desidratação, principalmente infantil. Existe um grande mercado para estes produtos, principalmente em regiões de climas quentes.

Assim, este trabalho teve como objetivo elaborar uma bebida repositora eletrolítica a base de permeado da ultrafiltração de leite e avaliar suas características físicas, químicas e microbiológicas durante o armazenamento por 30 dias, a $7^{\circ} \mathrm{C}$ e $25^{\circ} \mathrm{C}$.

\section{MATERIAL E MÉTODOS}

Permeado da ultrafiltração

O permeado utilizado foi obtido da ultrafiltração de leite desnatado pasteurizado $\left(65^{\circ} \mathrm{C}\right.$ 30 minutos $^{-1}$ ) no sistema de membranas do Laticínio Funarbe, localizado na Universidade Federal de Viçosa. O sistema de ultrafiltração (WGM Sistemas) foi equipado com membrana espiral de polisulfona/ poliamida de massa molar de corte de $10 \mathrm{kDa}$. Durante o processo de ultrafiltração, a temperatura do leite foi mantida entre 45 e $50^{\circ} \mathrm{C}$, com variação de pressão aplicada de 0,99atm, sendo a pressão de entrada de 2,96atm e a de saída de 1,97atm. A área filtrante da membrana foi equivalente a $6 \mathrm{~m}^{2}$. O permeado, filtrado, obtido do processo da ultrafiltração do leite, foi envasado em embalagens de polietileno com capacidade de 5 litros e estocado em freezer a $-20^{\circ} \mathrm{C}$, até posterior utilização na elaboração da bebida.Para produção da bebida, as amostras foram descongeladas, em refrigeração a $7^{\circ} \mathrm{C}$, por um período de 48 horas.

Elaboração da bebida

Para definição da formulação da bebida, foram realizados ensaios preliminares. $\mathrm{Na}$ elaboração da bebida, adicionaram-se ao permeado sacarose $(2 \% \mathrm{~m} / \mathrm{v}$, marca Vetec) e ácido cítrico $(0,4 \% \mathrm{~m} / \mathrm{v}$, marca Vetec), aplicando, na sequência, a pasteurização lenta $\left(65^{\circ} \mathrm{C} 30\right.$ minutos $\left.^{-1}\right)$. Após a pasteurização, a bebida foi resfriada rapidamente a $40^{\circ} \mathrm{C}$, quando foram adicionados benzoato de sódio $(0,05 \% \mathrm{~m} / \mathrm{v}$, marca Vetec), sorbato de potássio $(0,01 \% \mathrm{~m} / \mathrm{v}$, marca Vetec) e aroma artificial de limão $(0,05 \% \mathrm{v} / \mathrm{v}$, marca Duas Rodas). A bebida obtida foi envasada em garrafas de vidro de $316 \mathrm{~mL}$, previamente higienizadas (água em ebulição 20 minutos $^{-1}$ ), e armazenada em câmaras tipo BOD, a $7^{\circ} \mathrm{C}$ e $25^{\circ} \mathrm{C}$, por um período de 30 dias.

A determinação da concentração de sacarose adicionada na formulação foi baseada em testes preliminares, de forma que a osmolalidade estivesse dentro da faixa de $290 \mathrm{mOsm} \mathrm{L}^{-1}$ a 330mOsm $\mathrm{L}^{-1}$, sugerida por PETRUS \& FARIA (2005), em concordância com o limite máximo exigido pela ANVISA (2010), de 330mOsm L-1.

\section{Delineamento experimental}

Para análise das variáveis físicas e químicas durante a estocagem da bebida, utilizou-se um delineamento inteiramente casualizado, disposto em esquema de parcelas subdivididas, tendo na parcela as temperaturas de armazenamento $\left(7^{\circ} \mathrm{C}\right.$ e $\left.25^{\circ} \mathrm{C}\right)$ e na subparcela os tempos de armazenamento $(0,7,15$ e 30 dias). Portanto, teve-se como fonte de variação na parcela a temperatura de armazenamento e o erro (a) e, na subparcela, o tempo de armazenamento, a interação temperatura*tempo de armazenamento e o erro (b). A elaboração da bebida foi realizada em três repetições.

\section{Análises físicas e químicas}

As análises de $\mathrm{pH}$, acidez total titulável, água, proteínas, resíduo mineral fixo e sólidos solúveis totais foram realizadas segundo procedimentos descritos na Instrução Normativa 22 do Ministério da Agricultura (BRASIL, 2006). O teor de carboidratos totais foi obtido pela diferença percentual da soma dos demais nutrientes (proteína, resíduo mineral fixo e água). Para o cálculo do valor calórico, presente em $100 \mathrm{~mL}$ da bebida, multiplicaram-se os valores percentuais 
de carboidratos totais e proteínas das amostras pelos fatores calóricos 3,87 e 4,27, respectivamente, para leite (GOMES \& OLIVEIRA, 2011).

As concentrações de sódio e potássio foram determinadas por fotometria de chama (Sorning, 400), enquanto as de cálcio e magnésio por meio de absorção atômica (GBC, Avanta Sigma), utilizando-se de curvas analíticas para quantificação de cada mineral.

As concentrações de açúcares redutores e totais, expressos em percentagem de glicose, foram realizadas pelo método DNS (ácido 3,5-dinitrosalicílico) (MILLER, 1959).

A Osmolalidade foi determinada por crioscopia, segundo GOMES \& OLIVEIRA (2011), por meio de medidas do ponto de congelamento nas amostras das bebidas, utilizando-se o crioscópico (ITR modelo MK540). O cálculo da osmolalidade foi obtido pela seguinte equação:

Osmolalidade $\left(\mathrm{mOsmol} \cdot \mathrm{L}^{-1}\right)=\frac{\Delta T_{c}}{K_{c}} \cdot 1000$ em que $\mathrm{K}_{\mathrm{c}}=1,86^{\circ} \mathrm{C} \mathrm{mol}^{-1} \mathrm{~kg}^{-1}$ (constante crioscópica da água) e $\Delta \mathrm{T}_{\mathrm{c}}=$ temperatura no ponto de congelamento das amostras de bebidas.

$\mathrm{Na}$ análise objetiva da cor, foi utilizado o sistema de cor CIELAB, sendo os índices de cor $L^{*}, a^{*}$ e $b^{*}$, saturação $\left(C^{*}\right)$ e ângulo de tonalidade $\left(\mathrm{h}^{*}\right)$ determinados no aparelho ColorQuest II Sphere
Spectrophotometer (HunterLab, Reston, VA), conectado a um computador provido do sistema software Universal. O equipamento foi devidamente calibrado para reflectância incluída, ângulo de observador de $10^{\circ}$ e iluminante D65.

Análises microbiológicas

As análises microbiológicas foram realizadas, segundo metodologia da APHA (DOWES, 2001), sendo avaliadas as contagens de microorganismos mesófilos aeróbios, psicrotróficos, fungos filamentosos e leveduras e o número mais provável de coliformes $35^{\circ} \mathrm{C}$.

\section{Análises estatísticas}

Os dados foram interpretados por análise de variância (ANOVA), análise de regressão com análise da falta de ajustamento, para os modelos de $1^{\circ}$ e $2^{\circ}$ graus, e correlação de Pearsonao nível de $5 \%$ de probabilidade, utilizando o programa SAS (versão 9.2), licenciado para a Universidade Federal de Viçosa.

\section{RESULTADOS E DISCUSSÃO}

Caracterização química e física do permeado e da bebida isotônica

$\mathrm{Na}$ tabela 1, estão representados os valores médios e desvio-padrão dos resultados

Tabela 1 - Valores médios \pm desvio-padrão das variáveis físicas e químicas do permeado da ultrafiltração de leite e da bebida elaborada.

\begin{tabular}{|c|c|c|}
\hline Característica & Permeado & Bebida \\
\hline Proteínas $(\% \mathrm{~m} / \mathrm{v})$ & $0,087 \pm 0,01$ & $0,14 \pm 0,05$ \\
\hline Água $(\% \mathrm{~m} / \mathrm{v})$ & $97,36 \pm 0,04$ & $93,00 \pm 1,4$ \\
\hline Resíduo mineral fixo $(\% \mathrm{~m} / \mathrm{v})$ & $0,41 \pm 0,02$ & $0,38 \pm 0,10$ \\
\hline Carboidratos $(\% \mathrm{~m} / \mathrm{v})$ & $2,15 \pm 0,20$ & $6,48 \pm 1,18$ \\
\hline Sódio (mg L $\left.{ }^{-1}\right)$ & $374,4 \pm 0,9$ & $408,2 \pm 2,1$ \\
\hline Potássio $\left(\mathrm{mg} \mathrm{L}^{-1}\right)$ & $763,5 \pm 2,1$ & $769,5 \pm 7,8$ \\
\hline Cálcio $\left(\mathrm{mg} \mathrm{L}^{-1}\right)$ & $250,7 \pm 13,2$ & $243,4 \pm 32,8$ \\
\hline Magnésio (mg L $\left.{ }^{-1}\right)$ & $52,04 \pm 0,06$ & $48,4 \pm 3,2$ \\
\hline Valor Calórico (kcal em 100 mL) & - & 25,7 \\
\hline $\mathrm{pH}$ & $6,58 \pm 0,07$ & $3,42 \pm 0,22$ \\
\hline Acidez total titulável $(\% \mathrm{~m} / \mathrm{v})$ & $0,056 \pm 0,007^{(1)}$ & $0,66 \pm 0,015^{(2)}$ \\
\hline Osmolalidade $\left(\mathrm{mOsm} \cdot \mathrm{L}^{-1}\right)$ & $212,1 \pm 0,4$ & $311,6 \pm 0,7$ \\
\hline Sólidos solúveis ( ${ }^{\circ}$ Brix $)$ & - & $5,9 \pm 0,6$ \\
\hline Luminosidade (L*) & - & $61,42 \pm 0,56$ \\
\hline$a^{*}$ & - & $-2,67 \pm 0,33$ \\
\hline$b^{*}$ & - & $8,01 \pm 1,43$ \\
\hline Índice de saturação (c*) & - & $8,44 \pm 1,46$ \\
\hline Ângulo de tonalidade $\left(\mathrm{h}^{*}\right)$ & - & $108,50 \pm 0,99$ \\
\hline
\end{tabular}

\footnotetext{
${ }^{(1)}$ Expresso em \% de ácido lático; ${ }^{(2)}$ Expresso em \% de ácido cítrico.
} 
das análises físicas e químicas realizadas, para caracterizar o permeado da ultrafiltração de leite e a bebida.

A osmolalidade da bebida, de $311,6 \mathrm{mOsm}$ $\mathrm{L}^{-1}$, apresentou-se de acordo com o valor determinado pela resolução RDC nำ18, da ANVISA (BRASIL, 2010), que deve ser inferior a $330 \mathrm{mOsm} \mathrm{L}^{-1}$, e dentro da faixa sugerida por PETRUS \& FARIA (2005), para bebidas isotônicas. O teor de carboidratos, de $6,48 \%$,está adequado, segundo a resolução supracitada, que é de até $8 \%$. O reduzido teor de carboidratos e proteínas implicou na obtenção de um produto de baixo valor calórico, de $25,7 \mathrm{kcal}$ por $100 \mathrm{~mL}$, conferindo à bebida preferência de aquisição pelos consumidores.

Pode-se inferir que as vitaminas hidrossolúveis riboflavina, biotina, ácido pantotênico e nicotínico estão presentes no permeado e, consequentemente, vão compor a bebida como nutriente natural. Segundo DAMODARAN et al. (2010), essas vitaminas não apresentam perdas detectáveis durante o processo de pasteurização lenta.

Quantidades apreciáveis de sais inorgânicos simples de sódio, potássio e magnésio, naturalmente presentes no permeado conferiram à bebida formulada característica eletrolítica. Além disso, a presença do cálcio no permeado atribui à bebida um elemento fundamental para a saúde óssea e, em conjunto com o potássio, são importantes na regulação da atividade neuromuscular (WHITMIRE, 2002; MONTEIRO et al., 2004). Segundo MONTEIRO et al. (2004), o magnésio parece aumentar a resistência imunológica por prevenir infecções. CARVALHO et al. (2006) e WHITMIRE(2002) relatam que a presença de potássio evita câimbras e reidrata o indivíduo após a prática desportiva. Também pode ser empregado como diurético, contribuindo para a diminuição da pressão arterial de indivíduos com tendência à pressão alta e, juntamente com o sódio, participam da manutenção do equilíbrio hídrico normal.

Os valores encontrados para o sódio e para o potássio na bebida (Tabela 1) estão próximos daqueles estabelecidos na RDC nำ 18, da ANVISA (BRASIL, 2010), que dispõe sobre os suplementos hidroeletrolíticos para atletas.Entretanto, embora não seja um suplemento, a presença natural desses minerais no permeado confere à bebida característica de um repositor eletrolítico.

$\mathrm{O}$ valor de $\mathrm{pH}$ observado, de 3,4, foi igual ao encontrado por PETRUS \& FARIA (2005) em bebidas isotônicas formuladas convencionalmente, e semelhante ao verificado por DE MARCHI et al. (2003), de 3,2, em bebida isotônica natural de maracujá. O teor de sólidos solúveis encontrado para a bebida, de $5,9^{\circ}$ Brix, também é semelhante aos observados por PETRUS \& FARIA (2005), que variaram na faixa de 6,0 a $6,8^{\circ}$ Brix. No entanto, o valor da acidez total titulável encontrado neste estudo, de $0,66 \%$, foi superior ao resultado observado pelos estudos de PETRUS \& FARIA (2005), e próximos dos verificados por DE MARCHI et al. (2003), de 0,50\%.

Analisando o valor de $\mathrm{L}^{*}$, foi observado que a bebida apresentou-se clara. Valores negativos de $a^{*}$ e positivos de $b^{*}$, assim como os valores apresentados pelo ângulo de tonalidade $\left(h^{*}\right)$ e índice de saturação $\left(\mathrm{C}^{*}\right)$, no sólido de cor CIELAB, indicaram que a cor da bebida encontra-se entre amarelo e verde e se apresenta com baixa vivacidade. Isso se deve à riboflavina, pigmento presente no leite, que permanece no permeado, conferindo uma coloração natural ao produto final.

\section{Avaliação da vida de prateleira da bebida isotônica}

Os resultados das contagens microbiológicas de mesófilos aeróbios, psicrotróficos e fungos filamentosos e leveduras, além do número mais provável (NMP) de coliformes $35^{\circ} \mathrm{C}$, nas amostras de bebidas armazenadas nas temperaturas de $7^{\circ} \mathrm{C}$ e $25^{\circ} \mathrm{C}$, durante 30 dias, estão representados na tabela 2 .

A bebida apresentou contagem microbiológica relativamente baixa, com contagens inferiores a $10^{3} \mathrm{UFC} \mathrm{mL}^{-1}$ em todos os tempos e temperaturas avaliados. $\mathrm{O}$ número mais provável de coliformes também foi inferior a $3 \mathrm{NMP} \mathrm{mL}^{-1}$, indicando uma boa qualidade microbiológica da bebida. A resolução RDC nํㅜㄴ 2 da ANVISA (BRASIL, 2001) não estabelece padrões microbiológicos para repositores hidroeletrolíticos. Para sucos, refrescos, refrigerantes e bebidas não alcoolicas, exceto derivados de leite, a resolução recomenda que o produto esteja ausente de coliformes $35^{\circ} \mathrm{C}$, para amostra indicativa, o que está condizente com o resultado obtido. As baixas contagens de mesófilos aeróbios, fungos e leveduras também foram observadas por DE MARCHI et al. (2003), em bebidas isotônicas naturais de maracujá.

A baixa contagem inicial da bebida, o baixo valor de $\mathrm{pH}$ e a adição de conservantes químicos retardaram a multiplicação de micro-organismos. Portanto, do ponto de vista microbiológico, este não foi o fator determinante na vida de prateleira do produto, nas condições estudadas, e nem apresentou diferenças entre as duas temperaturas de armazenamento $(\mathrm{P}>0,05)$, indicando que a bebida poderia ser armazenada em temperatura ambiente. 
Tabela 2 - Contagens microbiológicas de mesófilos aeróbios, psicrotróficos, fungos filamentosos e leveduras e coliformes a $35^{\circ} \mathrm{C}$ em bebida elaborada com permeado da ultrafiltração de leite, estocada a $7^{\circ} \mathrm{C}$ e $25^{\circ} \mathrm{C}$, durante 30 dias.

\begin{tabular}{|c|c|c|c|c|c|}
\hline \multirow{2}{*}{ Microrganismos } & \multirow{2}{*}{$\mathrm{T}\left({ }^{\circ} \mathrm{C}\right)$} & \multicolumn{4}{|c|}{--Tempo (dias)- } \\
\hline & & 0 & 7 & 15 & 30 \\
\hline \multirow{2}{*}{ Mesófilos aeróbios (UFC mL ${ }^{-1}$ ) } & 7 & $3,9 \times 10^{2}$ & $4,3 \times 10^{2}$ & $4,2 \times 10^{2}$ & $8,8 \times 10^{1}$ \\
\hline & 25 & $4,2 \times 10^{2}$ & $3,1 \times 10^{2}$ & $4,7 \times 10^{2}$ & $5,0 \times 10^{1}$ \\
\hline \multirow{2}{*}{ Psicrotróficos (UFC mL $\left.{ }^{-1}\right)$} & 7 & $<1,0 \times 10^{1}$ & $<1,0 \times 10^{1}$ & $1,2 \times 10^{1}$ & $<1,0 \times 10^{1}$ \\
\hline & 25 & $1,0 \times 10^{1}$ & $9,7 \times 10^{1}$ & $7,7 \times 10^{1}$ & $<1,0 \times 10^{1}$ \\
\hline \multirow{2}{*}{ Fungos filamentosos e leveduras (UFC $\mathrm{mL}^{-1}$ ) } & 7 & $<1,0 \times 10^{1}$ & $2,7 \times 10^{1}$ & $<1,0 \times 10^{1}$ & $6,3 \times 10^{1}$ \\
\hline & 25 & $<1,0 \times 10^{1}$ & $<1,0 \times 10^{1}$ & $<1,0 \times 10^{1}$ & $2,7 \times 10^{1}$ \\
\hline \multirow{2}{*}{ Coliformes a $35^{\circ} \mathrm{C}\left(\mathrm{NMP} \mathrm{mL} \mathrm{m}^{-1}\right)$} & 7 & $<3$ & $<3$ & $<3$ & $<3$ \\
\hline & 25 & $<3$ & $<3$ & $<3$ & $<3$ \\
\hline
\end{tabular}

Não houve influência significativa da temperatura, do tempo de armazenamento e da interação entre o tempo e temperatura $(\mathrm{P}>0,05)$ sobre o pH (média de 3,4), acidez total titulável (média de $0,47 \%$ ) e sólidos solúveis totais (média de $6,5^{\circ}$ Brix) nas amostras de bebidas formuladas com o permeado da ultrafiltração de leite, avaliadas nas duas temperaturas teste e ao longo de 30 dias de armazenamento. PETRUS \& FARIA (2005) e DE MARCHI et al. (2003) também observaram que tais características não foram afetadas pelo tempo e temperatura de armazenamento em bebidas isotônicas.

As coordenadas de cor $\mathrm{L}^{*}, \mathrm{a}^{*}, \mathrm{~b}^{*}$ e $\mathrm{C}^{*}$ não sofreram influência significativa da temperatura e da interação entre tempo e temperatura $(\mathrm{P}>0,05)$, mas foram afetadas pelo tempo de armazenamento $(\mathrm{P}<0,05)$ (Figura 1). O ângulo de tonalidade, $\mathrm{h}^{*}$, entretanto, não foi afetado por nenhum fator $(\mathrm{P}>0,05)$, apresentando valor médio de 107,9.

A osmolalidade da bebida não foi alterada pela temperatura de armazenamento e a interação entre o tempo e a temperatura $(\mathrm{P}>0,05)$, mas houve aumento de sua medida ao longo do tempo de armazenamento $(\mathrm{P}<0,05)$. A concentração de açúcares redutores foi afetada pela temperatura e tempo de armazenamento, enquanto que concentrações de açúcares totais na bebida foram afetadas significativamente pelo tempo e interação entre os fatores $(\mathrm{P}<0,05)$. A alteração dessas variáveis ocorreu devido à hidrólise da sacarose, que libera dois moles de açúcares redutores (glicose e frutose) a cada mol hidrolisado. Isso implica aumento da concentração de solutos e, portanto, da osmolalidade da bebida e de açúcares redutores e totais durante seu armazenamento. Apesar da variação ocorrida, os valores de osmolalidade não ultrapassaram o valor de $330 \mathrm{mOsm} \mathrm{L}^{-1}$, em ambas as temperaturas de armazenamento.

Foram observadas correlações positivas $(\mathrm{P}<0,05)$ entre a concentração de açúcares redutores e totais com a osmolalidade, como representado na figura 2. Isso indica que, à medida que a osmolalidade da bebida aumenta, há também um aumento dos açúcares totais, de maneira mais intensa do que o aumento de açúcares redutores. Essa correlação se deve ao fato de que a osmolalidade do produto aumenta em função do aumento dos açúcares redutores e totais, devido à inversão da sacarose ocorrida durante o armazenamento da bebida.

\section{CONCLUSÃO}

A matéria-prima neste estudo é tratada como resíduo da indústria e comumente descartada em efluentes, surtindo efeitos prejudiciais ao meio ambiente. Suas características osmolíticas e presença de minerais naturais do permeado da ultrafiltração de leite constitui um produto promissor para fabricação, em larga escala, de um reidratante com fins de reposição de eletrólitos após a atividade física.

Além disso, no estudo de vida de prateleira, a bebida mostrou-se estável microbiologicamente, assim como ligeiras alterações físicas e químicas em sua composição não descaracterizaram o produto armazenado em temperatura ambiente.

\section{AGRADECIMENTOS}

Os autores agradecem à Fundação de Amparo à Pesquisa do estado de Minas Gerais (FAPEMIG), pela concessão de recursos financeiros para realização do projeto, e ao Conselho Nacional de Desenvolvimento Científico e Tecnológico (CNPq), pelo auxílio com a bolsa de iniciação científica. 


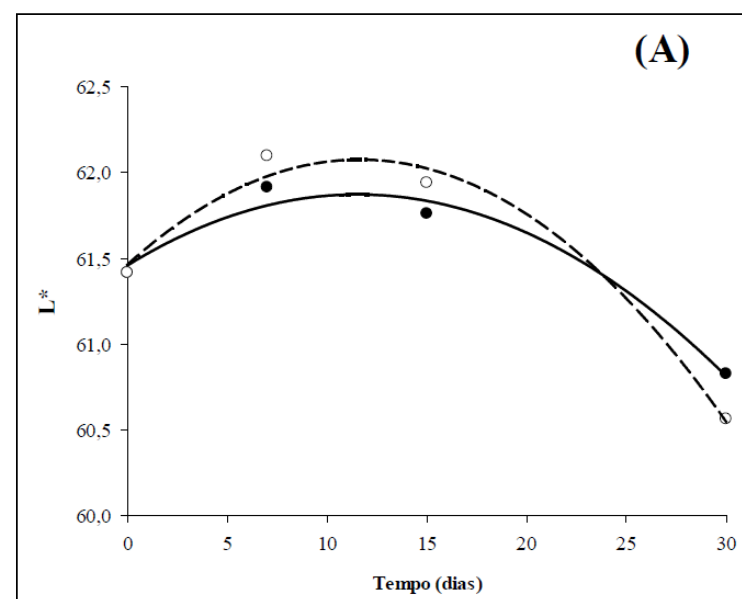

(B)

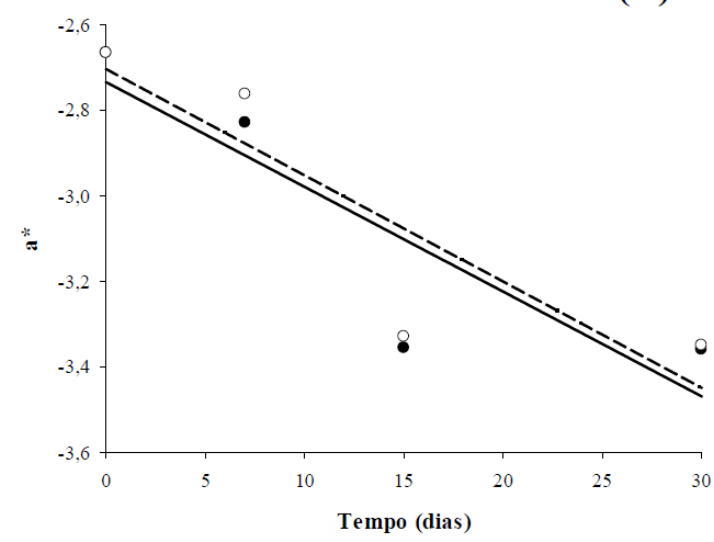

(C)

(D)
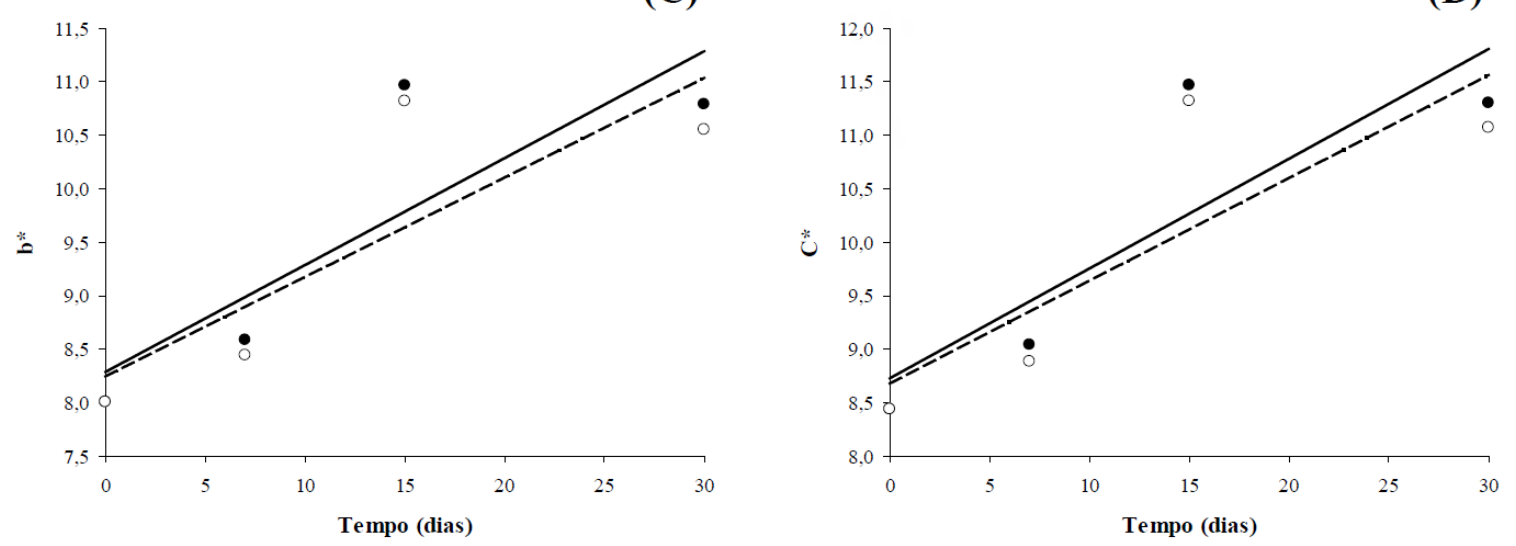

Figura 1 - Variação das coordenadas de cor $\mathrm{L}^{*}, \mathrm{a}^{*}, \mathrm{~b}^{*}$ e C*,em função do tempo, em bebidas armazenadas a $7^{\circ} \mathrm{C}\left(\longrightarrow-\right.$ - $25^{\circ} \mathrm{C}(--\circ--)$ no período de 30 dias.
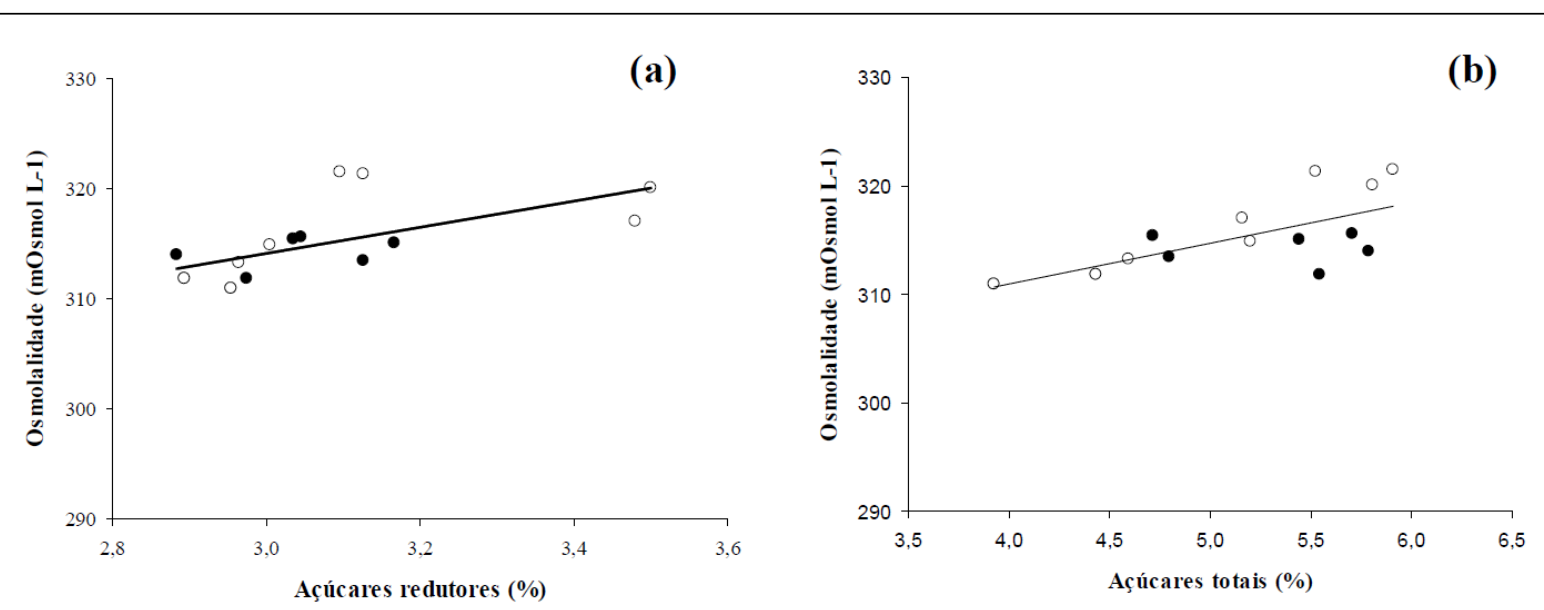

Figura 2 - Correlação entre a osmolalidade e a concentração de açúcares redutores (a) e totais (b) em bebidas formuladas a base de permeado de ultrafiltração de leite, durante o período de armazenamento de 30 dias a $7^{\circ} \mathrm{C}(\bullet)$ e $25^{\circ} \mathrm{C}(\circ) \cdot \mathrm{r}_{(\mathrm{a})}=0,6405 ; \mathrm{n}=16$; $\mathrm{P}<0,05 . \mathrm{r}_{(\mathrm{b})}=0,7148 ; \mathrm{n}=16 ; \mathrm{P}<0,05$. 


\section{REFERÊNCIAS}

BALDASSO, C.et al. Concentration and purification of whey proteins by ultrafiltration. Desalination, v.278, p.381386, 2011. Disponível em: <http://www.sciencedirect.com/ science/journal/00119164/278/1-3>. Acesso em: 13 ago 2011. doi:10.1016/j.desal.2011.05.055.

BRASIL. Resolução RDC n 18 , de 27 de Abril de 2010. Dispõe sobre alimentos para atletas. Diário Oficial da União, Brasília, 28 de abril de 2010

BRASIL. Instrução Normativa nº 68 , de 12 de Dezembro de 2006. Oficializa os métodos analíticos oficiais físico-químicos, para controle de leite e produtos lácteos. Diário Oficial da União, Brasília, 13 de dezembro de 2006.

BRASIL. Resolução RDC $\mathrm{n}^{\circ} 12$, de 2 de janeiro de 2001. Regulamento técnico sobre padrões microbiológicos para alimentos. Diário Oficial da União, Brasília, 10 de janeiro de 2001.

CARVALHO, J.M. et al. Composição mineral de bebida mista a base de água de coco e suco de caju clarificado. BCEPPA, v.24, n.1, p.1-12, 2006.

DAMODARAN, S. et al. Química de alimentos de Fennema. 4ed. Porto Alegre: Artmed, 2010. 900p.

DE MARCHI, R.et al. Avaliação da Vida-de-Prateleira de um Isotônico Natural de Maracujá (Passiflora edulis Sims. f. flavicarpaDeg.). Brazilian Journal of Food Technology, v.6, n.2, p. 291-300, 2003. Disponível em: <http://www.ital.sp.gov.br/ bj/artigos/brazilianjournal/free/p03144.pdf>. Acesso em:25 mar. 2012 .

DOWES, F.P.; ITO, K. (Eds.). Compedium of methods for the microbiological examination of foods. 4.ed.Washington, DC: American Public Health Association, 2001.676p.

GOMES, J.C.; OLIVEIRA, G.F. Análises físico-químicas de alimentos. Viçosa: UFV, 2011. 303p.
MILLER, G.L. Use of dinitrosalicylic acid reagent for determination of reducting sugar. Analytical Chemistry, v.31, p.426-428, 1959.Disponível em: <http://nsrdec.natick.army.mil/ LIBRARY/59-69/R59-36.pdf>. Acesso em:22 nov. 2010.

MONTEIRO, J.B.R. et al. Avaliação da qualidade protéica de dois formulados em pó, à base de soja enriquecidos com zinco, selênio e magnésio para utilização em nutrição enteral. Ciência e Tecnologia Alimentos, v.24, n.1, p.006-010, 2004. Disponível em: $<$ http://www.scielo.br/pdf/cta/v24n1/20032.pdf $>$. Acesso em:11 abr. 2012.

NETO, R.J. Avaliação tecnológica e físico-química de queijo tipo minas frescal obtido a partir do leite concentrado por ultrafiltração. 2006. 66 f Dissertação (Mestrado em Engenharia de Alimentos) - Curso de pós-graduação em Engenharia de Alimentos, Universidade Federal de Santa Catarina, SC.Disponível em: $<$ https:// repositorio.ufsc.br/bitstream/handle/123456789/89426/236505. pdf?sequence $=1>$. Acesso em: 23 mai. 2010.

PETRUS, R.R.; FARIA, J.A.F. Processamento e avaliação de estabilidade de bebida isotônica em garrafa plástica. Ciência e Tecnologia Alimentos, v.25, n.3, p.518-524, 2005.Disponível em: $<$ http://www.scielo.br/pdf/cta/v25n3/27021.pdf $>$. Acesso em: 11 out. 2012.

SARON, M.L.G. Aproveitamento do permeado de soro de leite bovino através da transformação da lactose em lactulose e como ingrediente para meios de cultura de bactérias probióticas. 2003. 107f. Dissertação (Mestrado em Alimentos e Nutrição) - Faculdade de Engenharia de Alimentos, Universidade Estadual de Campinas, SP.

VEIGA, P.G.; VIOTTO, W.H. Fabricação de queijo petit suisse por ultrafiltração de leite coagulado. Efeito do tratamento térmico do leite no desempenho da membrana. Ciência e Tecnologia de Alimentos, v.3, n.21, p.267-272, 2001.Disponível em: <http:// www.scielo.br/pdf/cta/v21n3/8541.pdf>. Acesso em:13 ago. 2011.

WHITMIRE, S.J. Água, eletrólitos e equilíbrio ácido-base. In: MAHAN, L.K.; SCOTT-STUMO,S. Krause: alimentos, nutrição e dietoterapia. 10.ed. São Paulo:Roca, 2002.p.146-156. 